\title{
Exploring the Relationship Between Community Program Location and Community Needs
}

\author{
Hannab Shadowen, MPH, Kristen O'Loughlin, MS, MA, Kelly Cheung, \\ William Thornton, MS, MBA, Alicia Richards, Roy Sabo, PhD, Jennifer Hinesley, PsyD, \\ and Alex H. Krist, $M D, M P H$
}

Introduction: Health behaviors, mental health, and social needs impact health, but addressing these needs is difficult. Clinicians can partner with community programs to provide patients support. The relationship between program location and community need is uncertain.

Methods: We identified and geolocated community programs in Richmond, Virginia, that aid with 9 domains of needs (mental health, smoking, unhealthy alcohol use, nutrition, physical activity, transportation, financial, housing, food insecurity). For each census tract, we identified needs from public data sources. We used 2 methods to compare program location and need: (1) hotspot analysis and (2) a negative binomial regression model.

Results: We identified 280 community programs that provide aid for the 9 domains. Programs most often provided financial assistance $(n=121)$ and housing support $(n=73)$. The regression analysis showed no relationship between the number of community programs and the level of need in census tracts, with 2 exceptions. There was a positive association between financial programs and financial need and a negative association between housing programs and housing need.

Conclusions: Community programs are generally not colocated with need. This poses a barrier for people who need help addressing these domains. (J Am Board Fam Med 2022;35:55-72.)

Keywords: Family Medicine, Food Insecurity, Geospatial Analysis, Health Behavior, Housing, Mental Health, Social Determinants of Health

\section{Introduction}

Poor health behaviors, mental health, and social needs are common among US adults and impact health and well-being. In the United States, $78 \%$ of adults exercise inadequately, $14 \%$ smoke, and 20\% binge drink an average of 4 times per month. ${ }^{1-3} \mathrm{~A}$ third of preventable deaths are caused by physical inactivity, tobacco use, unhealthy diet, and unhealthy

This article was externally peer reviewed.

Submitted 19 July 2021; revised 26 August 2021; accepted 9 September 2021.

From the Department of Health Behavior and Policy, Virginia Commonwealth University, Richmond, VA (HS); Department of Psychology, Virginia Commonwealth University, Richmond, VA (KO); Department of Biostatistics, Virginia Commonwealth University, Richmond, VA (AR, RTS); Department of Family Medicine and Population Health, Virginia Commonwealth University, Richmond, VA (JH, KC, AHK); YMCA of Greater Richmond, Richmond, VA (W'T).

Funding: Funding for this study is provided by the Agency for Healthcare Research and Quality (1R01HS026223-01) and the National Center for Advancing Translational Sciences (UL1TR002649). The opinions expressed in this manuscript are those of the authors and do not necessarily reflect those of the funders. alcohol use. ${ }^{4}$ Almost 1 in 5 US adults have a mental illness, but only $40 \%$ of these adults receive any treatment. ${ }^{5}$ Social needs are common. For example, $35 \%$ of adults experience stress about housing needs and $32 \%$ experience stress over transportation needs. ${ }^{6}$ Multiple organizations have called for primary care and public health to better address social needs. ${ }^{6-11}$

While primary care is seeking to address health behaviors, mental health, and social needs, doing so is complex and requires coordination with programs beyond the health care setting. One solution is for health systems and clinicians to partner with social services, public health, and community-based organizations to assist patients with these core needs. Examples include Prescription for Health,

Conflict of interest: The authors of this manuscript have no conflicts of interest to disclose.

Corresponding author: Hannah Shadowen, MPH, Department of Health Behavior and Policy, Virginia Commonwealth University, 907 Floyd Ave, Richmond, VA 23284 (E-mail: shadowenhm@vcu.edu). 
Health Leads, and Accountable Care Communities. $^{10,12-16}$ In addition, resource registries are emerging that comprehensively catalog local programs and even offer electronic and automated referral mechanisms to better connect patients to programs and allow clinicians to coordinate health behavior, mental health, and social care with clinical care. ${ }^{17,18}$ Virginia has allocated $\$ 10$ million in federal Coronavirus Aid, Relief, and Economic Security Act funding to create Unite Virginia, a statewide technology platform to help clinicians connect vulnerable Virginians with social services. ${ }^{19}$

Despite these efforts, few patients connect with services when referred from the clinical setting. ${ }^{20}$ One potential barrier for patients is program accessibility. Location may influence program access, as transportation is often lacking. ${ }^{21}$ While the physical proximity of programs to areas of need is important, many communities have not systematically assessed the geographic distribution of their programs and how well they match with the community's needs. The aim of this study is to understand the relationship between community program location and community need through 2 methodologies: (1) hotspot analysis and (2) binomial regression. This approach could serve as a template for future community planning to improve service delivery.

\section{Methods}

This article reports a secondary analysis of data collected as part of a randomized controlled trial to test an enhanced care-planning process to better control chronic conditions. The secondary analysis compares the locations of community programs that address health behavior, mental health, and social needs to locations of community needs using 2 different techniques: hotspot analysis and binomial regression analysis.

The locations of community programs were determined as part of the development of the enhanced care-planning intervention, which includes guiding patients through a health risk assessment and creating a personalized care plan using the My Own Health Report (MOHR) online tool, ${ }^{22-24}$ support from a patient navigator and community health worker, and connection to community programs to help address patient goals. The MOHR risk assessment and care-planning tool includes 15 domains spanning health behaviors, mental health, and social needs (nutrition, physical activity, smoking, unhealthy alcohol use, unhealthy drug use, mental health, loneliness, sleep, housing, food insecurity, transportation, finances, dental care, safety, and health education). ${ }^{25}$ These domains (and their risk assessment questions) were the social and behavioral measures recommended by the National Academies of Sciences, Engineering, and Medicine to include in electronic health records. ${ }^{22,26,27}$

\section{Community Needs Identification}

We used publicly available data sources to classify community needs at the census tract level. We identified community need metrics for 9 of the 15 domains (nutrition, physical activity, smoking, unhealthy alcohol use, mental health, housing, food, transportation, finances) based on common metrics within the literature such as the 500 Cities Project Methodology, the Food Access Research Atlas, and the Eviction Lab. We chose these specific 9 domains because the other 6 domains of need did not have appropriate publicly available data at the census tract level. The specific measures for each of the chosen 9 domains are shown in Table 1. We used American Community Survey data for 2018 to assess financial and transportation needs $;^{28}$ data from the 500 Cities Project to assess mental health, unhealthy alcohol use, physical activity, obesity, and smoking needs; ${ }^{29}$ the Food Access Research Atlas to assess food insecurity; ${ }^{30}$ and data from the Eviction Lab to assess housing needs. ${ }^{31}$

\section{Community Program Identification}

In the summer and fall of 2019, a team of 12 researchers, staff, and students used a 4-step process modeled after CommunityRx, an e-prescribing tool for connecting patients to community resources that assist with wellness and disease management, to identify all available community programs in Richmond city that could aid patients in any of the 15 domains. ${ }^{32}$ First, the team identified programs from 3 local resource registries: VCU Health System, Findhelp.org, and the local YMCA of Greater Richmond. Second, clinicians and social workers at practices participating in the Virginia Ambulatory Care Outcomes Research Network were asked to identify the programs they use in clinical care. Third, select programs were contacted to identify partner organizations with which they 
Table 1. Number of Community Programs Identified and Identified Community Needs in Richmond, Virginia, in the Summer and Fall of 2019

\begin{tabular}{|c|c|c|c|}
\hline Domain & $\begin{array}{l}\text { Number of Programs } \\
\text { Geolocated in Richmond }\end{array}$ & $\begin{array}{c}\text { Metric for Assessing Community Need by } \\
\text { Census Tract* }\end{array}$ & $\begin{array}{l}\text { Mean Value (SD) of } \\
\text { Need by Census Tract }\end{array}$ \\
\hline Mental health & 47 & $\begin{array}{l}\text { Percent of adults reporting } 14 \text { days per } \\
\text { month when mental health was not } \\
\text { good }\end{array}$ & $13.7 \%(3.7 \%)$ \\
\hline Smoking & 11 & $\begin{array}{l}\text { Percent of adults who are past or current } \\
\text { smokers }\end{array}$ & $20.3 \%(6.7 \%)$ \\
\hline Unhealthy alcohol use & 35 & $\begin{array}{l}\text { Percent of adults with } \geq 1 \text { binge drinking } \\
\text { episode in past month }\end{array}$ & $17.2 \%(4.62 \%)$ \\
\hline Nutrition & 56 & $\begin{array}{l}\text { Percent of adults with body mass } \\
\text { index } \geq 30 \mathrm{~kg} / \mathrm{m}^{2}\end{array}$ & $33.3 \%(8.98 \%)$ \\
\hline Physical activity & 32 & $\begin{array}{l}\text { Percent of adults with no leisure time } \\
\text { physical activity }\end{array}$ & $26.7 \%(9.99 \%)$ \\
\hline Transportation & 20 & $\begin{array}{l}\text { Percent of households with no vehicle } \\
\text { available }\end{array}$ & $10.6 \%(12.9 \%)$ \\
\hline Financial & 121 & $\begin{array}{l}\text { Percent of residents below } 100 \% \text { poverty } \\
\text { level }\end{array}$ & $24.9 \%(16.8 \%)$ \\
\hline Housing & 73 & $\begin{array}{l}\text { Percent of renter-occupied units with an } \\
\text { eviction judgement annually }\end{array}$ & $12.1 \%(8.33 \%)$ \\
\hline Food insecurity & 67 & Designated as a food desert & 11 of 66 census tracts \\
\hline
\end{tabular}

Abbreviation: SD, standard deviation.

Notes: Some resources provided more than one service, so the total number of resources does not sum to 280.

${ }^{*}$ Data sources for community metrics include the American Community Survey for 2018 (financial, transportation), ${ }^{28} 500$ Cities Project data for 2018 (mental health, alcohol use, physical activity, obesity, smoking), ${ }^{29}$ Food Access Research Atlas (food insecurity), ${ }^{30}$ and the Eviction Lab (housing). ${ }^{31}$

collaborate. Finally, the team conducted Internet searches and used personal knowledge of the communities to identify additional resources.

These programs were entered into a REDCap database, including their mailing address, domains addressed, eligibility criteria, willingness to accept insurance, cost, and contact information. Throughout each step of program identification, the database was shared with partners for review and input. ${ }^{33}$ For each community program, we identified the longitude and latitude from the listed address using the Census.gov Geocoder. If no longitude or latitude was returned, we manually collected the information from https://www.latlong. net/. Community programs outside Richmond city census tracts or with no identifiable latitude and longitude were excluded from the binomial regression and the hotspot analysis. Only the community program's listed address of service was included.

\section{Hotspot Analysis}

We used descriptive geographic information system mapping techniques to assess the spatial distribution of community need and community programs for each domain. As shown in the Appendix, we created thematic maps of community need represented by quintile natural breaks and overlaid relevant community programs for each domain.

Next, we conducted 2 individual hotspot analyses of (1) community needs and (2) community programs and then overlayed the corresponding 2 analyses for each domain using ArcMAP 10.8.1. We only included domains with at least 30 identified community programs (the minimum size required for the hotspot analysis). For the community program hotspot analysis, we identified areas with a higher or lower density of community programs than average using an optimized hotspot analysis with the following parameters: count incidents with the hexagon grids as the unit of analysis, distance band of 1 mile, and Richmond city as the bounding polygon.

For the community need hotspot analysis, we first used the incremental spatial autocorrelation test to identify the appropriate distance threshold that functions as the scale of analysis. We chose the distance threshold where all features had at least 1 neighbor and where clustering was most intense (peak of the z-score) using the global Moran I test. Once we identified this distance threshold, we used the optimized hotspot analysis with the following parameters: the distance threshold identified as 
described above and census tract as the polygon unit. The hotspot analysis on community need excluded food insecurity as it was a dichotomous variable.

For both hotspot analyses we used Getis-Ord $\mathrm{Gi}^{*}$ statistics to identify the significant clusters of either census tracts or hexagon grids with a false discovery corrected $P$ value $<0.10 .{ }^{34}$ Community need hotspots and coldspots were statistically significant clusters of census tracts with higher or lower rates of community need, respectively, than would be expected given a random distribution of community need. Community program hotspots and coldspots were similarly defined as clusters of hexagons with significantly greater or lower number of programs, respectively, than would be expected given a random distribution of programs.

Next, we layered the hotspots and coldspots for community programs and community need to identify any overlapping areas. We then conducted sensitivity analyses to determine how sensitive the overlap was to the parameter specifications of the hotspot analysis. We used the default distance threshold generated in the optimized hotspot analysis and a distance threshold of 0.75 miles for community programs as well as the default distance identified with the optimized hotspot tool for community need. These results can be found in the Appendix.

\section{Negative Binomial Regression Analysis}

Based on their longitude and latitude, we measured the number of community programs located within a radius of the center of the census tract. Radii of 0.5 and 1.0 miles were used to reflect the range of acceptable walking distances within the literature. Acceptable walking distances vary between 0.25 to 1.0 miles by subgroup and by destination, so 2 radii were chosen to reflect this broad variation in walking distances. ${ }^{35,36}$ Negative binomial regression models were used to estimate associations between the number of community programs (count outcome) and the level of community need, adjusted for racial distribution and life expectancy. We used negative binomial regression because our outcome was count data, and this model accounted for high variation in the data by adjusting the variance independently from the mean. We adjusted for racial distribution, as previous work shows increased density of community programs is associated with a larger proportion of White residents. ${ }^{37-39} \mathrm{We}$ adjusted for life expectancy to control for the general health status of the area. Both racial distribution and life expectancy aim to control for baseline health and systemic racism. For each community need, a model was fit for outcomes defined using both the 0.5 -mile and 1.0-mile distances. For each model, the relative risk, $95 \% \mathrm{CI}$, and $P$ value were reported. All analyses were performed at a statistical significance level of 0.05 and used SAS Version 9.4 Statistical Software (SAS Institute, Cary, NC) and R 3.6.1.

\section{Results}

In total, we identified 314 community programs that had an identifiable latitude and longitude in the city of Richmond and that addressed 1 of the 15 domains included in MOHR. Of these, 280 programs addressed 9 of the domains included in the binomial regression analysis and 272 programs addressed the 7 domains included in the hotspot analysis. Financial assistance was the most common domain addressed by the programs $(n=121)$ and smoking cessation the least common $(\mathrm{n}=11)$ (Table 1). Similarly, the domain with the most census tracts that had programs within a 1-mile and 0.5 -mile radius of the centroid of the census tract was financial resources $(n=36$ census tracts for 1 mile and $\mathrm{n}=33$ census tracts for 0.5 -mile radius) (Table 2).

When examining our thematic maps, we discovered that high community need was located in similar parts of Richmond across all domains except for binge drinking and food deserts (Figure S1). For example, the northwest part of Richmond had

Table 2. Percent of Census Tracts $(n=66)$ with a Community Program within One or One-Half Miles Radius from the Centroid in Richmond, Virginia, in the Summer and Fall of 2019

\begin{tabular}{lcc}
\hline Domain & 1-Mile Distance & 0.5-Mile Distance \\
\hline Mental health & 23 & 18 \\
Smoking & 5 & 5 \\
Unhealthy alcohol use & 17 & 14 \\
Nutrition & 25 & 21 \\
Physical activity & 16 & 13 \\
Transportation & 13 & 10 \\
Financial & 36 & 32 \\
Housing & 29 & 20 \\
Food insecurity & 33 & 29 \\
\hline
\end{tabular}


Figure 1. Hotspots of community program density and needs in Richmond, Virginia, by domain in the summer and fall of 2019.

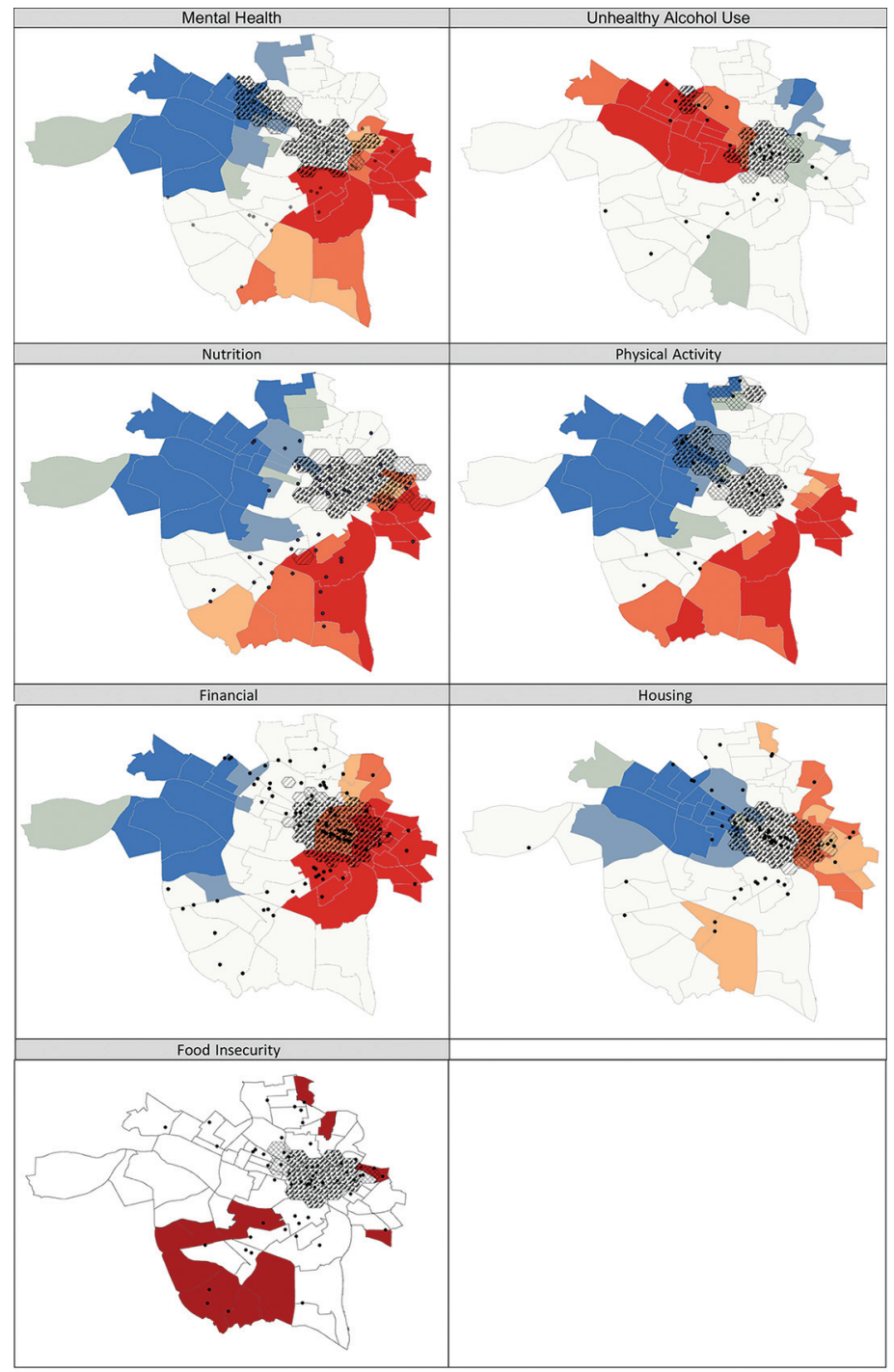

\section{Community Need}

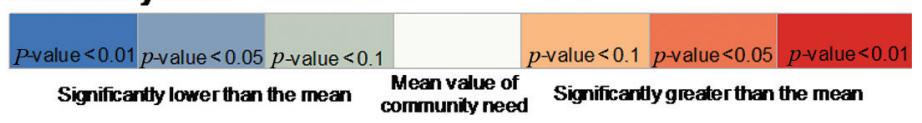

Density of community programs

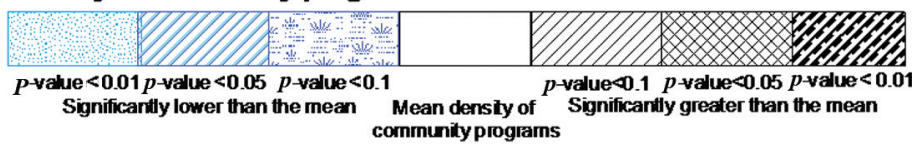

Hotspots of community programs (black hashes) are geospatially mapped in relation to

community needs hotspots (red) versus community needs coldspots (blue). Hotspots of

community programs are no more likely to be in or near hotspots or coldspots of greater

community need for housing, food insecurity, nutrition, mental health, and alcohol use. For

finance, community program hotspots are more likely to be located in hotspot of community

need and not in coldspots of community need. For physical activity, community programs were

located in coldspot of community need and not in hotspot of community need. 
Table 3. Binomial Regression Model to Identify Relationship Between Levels of Community Need and Density of Service Programs in Richmond, Virginia, in the Summer and Fall of 2019

\begin{tabular}{|c|c|c|}
\hline Services Domain & $\begin{array}{l}\text { 1-Mile Distance from Centroid } \\
\text { Relative Risk (95\% CI) }\end{array}$ & $\begin{array}{c}\text { 0.5-Mile Distance from Centroid } \\
\text { Relative Risk }(95 \% \mathrm{CI})\end{array}$ \\
\hline Mental health & $1.22(0.94-1.57)$ & $1.17(0.89-1.52)$ \\
\hline Smoking & $1.12(0.70-1.80)$ & $1.08(0.76-1.53)$ \\
\hline Unhealthy alcohol use & $1.45(0.99-2.13)$ & $1.39(0.94-2.06)$ \\
\hline Nutrition & $0.97(0.84-1.12)$ & $0.91(0.76-1.08)$ \\
\hline Physical Activity & $0.97(0.84-1.13)$ & $0.95(0.80-1.12)$ \\
\hline Transportation & $1.02(0.95-1.09)$ & $1.03(0.96-1.10)$ \\
\hline Financial & $1.05(1.02-1.08)^{*}$ & $1.06(1.03-1.10)^{*}$ \\
\hline Housing & $0.87(0.77-0.98)^{*}$ & $0.84(0.70-1.00)$ \\
\hline Food insecurity & $0.54(0.18-1.56)$ & $0.53(0.16-1.71)$ \\
\hline
\end{tabular}

Abbreviation: CI, confidence interval.

Notes: (1) Adjusted for percent Black residents and life expectancy of census tract. (2) In the binomial regression model, there were no significant relationships between location of community programs and percent Black residents or life expectancy of census tracts.

*Bold shaded cells statistically significant $(P$ value $<0.05)$.

lower unemployment, lower poverty rate, fewer poor mental health days, less physical inactivity, and lower obesity rate, whereas the eastern part of Richmond had higher rates of these community needs. The exception to this trend was seen in unhealthy alcohol use, with a higher prevalence of binge drinking in the northwest of Richmond and lower prevalence of binge drinking in the northeastern region (Appendix Figure 1).

As seen in Figure 1, colocation of community program hotspots and community need hotspots varied across domains. For financial need, program location hotspots extended into the hotspots of the poverty rate and did not extend into coldspots of the poverty rate. In contrast, physical activity program location hotspots only extended into coldspots of physical inactivity, suggesting a discordance between need and program location. Programs assisting with food insecurity were primarily located outside of food deserts and extended into only a small portion of 1 census tract categorized as a food desert. For mental health, unhealthy alcohol use, nutrition, and housing insecurity, we observed mixed correspondence between hotspots and coldspots for program location and community need.

In the hotspot sensitivity analysis, physical activity showed inconsistencies based on parameter specifications. For example, when using the default distance threshold for both the physical inactivity rate and community programs, the program hotspots extended into both coldspots and hotspots of physical inactivity, but when using a 0.75 -mile distance threshold for community programs and the distance threshold of peak clustering for community need, the program hotspots only extended into coldspots of physical inactivity (Appendix Figure 5). For financial assistance, the hotspots of financial programs did not overlap any coldspots for poverty regardless of parameter specifications (Appendix Figure 6). For food insecurity, mental health, nutrition, housing insecurity, and unhealthy alcohol use, the program hotspots overlapped both hotspots and coldspots of need in all parameter specifications, but the degree of overlapped changed based on the parameter specifications (Appendix Figures 2-4, 7, and 8).

The binomial regression analysis also found poor correspondence between program locations and levels of need. We found no statistically significant association between community need and the number of community programs for nutrition, physical activity, smoking, food insecurity, transportation, unhealthy alcohol use, and mental health (Table 3). A positive association was observed between poverty rates and the number of financial programs, at both the 1.0 -mile radius $(\mathrm{RR}=1.05$, $95 \% \mathrm{CI}, 1.02-1.08)$ and 0.5 -mile radius $(\mathrm{RR}=1.06$, $95 \%$ CI,1.03-1.10). There was a negative association between community eviction rates and the number of housing programs at the 1.0-mile radius $(\mathrm{RR}=0.87,95 \%$ CI, 0.77-0.98); while the magnitude of the association was larger at the 0.5 -mile radius, it was statistically weaker $(\mathrm{RR}=0.84,95 \% \mathrm{CI}$, 0.70-1.00). 


\section{Discussion}

While we identified 314 community programs in the city of Richmond that can help people with 9 domains of need involving health behaviors, mental health, and social problems, the programs were generally not situated in areas with the greatest needs. We found no statistically significant relationship between the number of programs and levels of need for food insecurity, nutrition, mental health, unhealthy alcohol use, transportation, or smoking. The only exception involved programs for financial needs, where a positive association between location and need was observed in both the hotspot analysis and binomial regression results. A complete mismatch between location and needs was in the hotspot analysis for physical activity; programs were more likely to be in census tracts with higher levels of physical activity. The binomial regression analysis found that housing resources were less available in communities with higher eviction rates.

The few studies that have examined this topic have also reported inequities between community program locations and community need. For example, Davis et al. found low access to foods in an urban area with high need; specifically, only $41 \%$ of WIC participants had access to an authorized WIC store. ${ }^{40}$ Zenk et al found that communities with the largest concentration of Black residents and highest poverty rates were further from the nearest supermarket than those with the fewest Black residents and least poverty. ${ }^{41}$ Estabrooks et al. found that areas of high socioeconomic status had access to more physical activity resources than those of middle or low socioeconomic status. ${ }^{42}$ The exception we observed regarding financial programs was seen in at least 1 other study. In Boston, Bauer et al. found that the density of services offering financial assistance was higher in block groups with a higher poverty rate. ${ }^{43}$

Geographic location is known to influence use of behavioral health services and health behaviors. For example, proximity to care was positively associated with mental health care follow-up after inpatient substance abuse treatment and with receipt of methadone at opioid treatment programs. ${ }^{44,45}$ Increased travel time is associated with fewer visits to a mental health care provider and reduced receipt of guideline-concordant care. ${ }^{46}$ The same principle applies to resources for healthy behaviors.
For example, the amount of park space within 1 mile of home addresses was associated with physical activity and the number of exercise facilities within 1 kilometer of home addresses was associated with increased gym membership and physical activity. ${ }^{47,48}$

Our study has some limitations. First, the sample size for some domains was small, which may limit power to detect relationships between location and need. However, our findings are consistent across both analytic methods and mirror previous research. In addition, geospatial analyses focus on distance between locations and cannot account for dynamic variables such as connectedness between communities (eg, public transportation), ability for residents to move between areas, or travel time due to traffic. We focused on listed addresses for the community programs and were not able to include other outreach efforts such as through vans or popup clinics, which was beyond the scope of this project. By their nature, outreach efforts are highly fluid and vary greatly by time. Further, some domains such as mental health may have little outreach, whereas food insecurity may have more. Last, we did not examine the impact of a community program's ability to electronically connect with providers, which may be an important element of successful referrals from a provider to a patient. This electronic contact between health care providers and community programs needs to be examined in future studies.

Our study has several strengths. First, we used 2 unique analytic methods to examine geographic relationships. The consistency of findings across both methods demonstrates robustness. Second, by demonstrating consistent findings for multiple radiuses of distance ( 0.5 and 1.0 miles) in the binomial regression, we can infer a similar barrier for individuals who can travel different distances. These 2 methods can complement each other and strengthen conclusions from each method. Third, while several studies have examined discordance between location and need in 1 domain, ours is the first to consider multiple domains at once and thereby expose a recurring regional problem of the location of service programs. Fourth, our study used detailed indicators of need for each domain rather than general measures of socioeconomic status or poverty. Finally, this study broadens the geographic diversity of the literature, as no prior studies on this 
topic have been conducted in Virginia or even the South.

We demonstrate that for the majority of domains, resources are not exclusively located in areas of high need. Using tools such as the mapping techniques in this article can be used to target the location of future programs. While it is important to understand the discordance between location and need, we cannot ignore the realities that created them. Therefore, to reduce these discordances, it will most likely require incentives to encourage the development of and the maintenance of community programs in locations where they are most needed. This could come in the form of tax incentives or policy decisions to encourage development in needed areas. However, quantifying these mismatches is the first step in reducing the discordance and improving geographic access to resources.

\section{Conclusion}

In Richmond, Virginia, community programs to help people with health behaviors, mental health, and social needs are not located where they are most needed, with the 1 exception of financial assistance. Travel distance can prevent people from accessing these needed programs, making it important for communities to use methods like ours to define places of greatest need and locate resources where they can have maximum impact.

We would like to thank the following students for assisting with community program identification: Sanjoli Agarwal, Karina Armenta, Leslie Chavez, Jiabi Chen, Charlotte Crider, Ola Dinakin, Amy He, Samantha Lee, Martaya Napper, Hannah Rak, Kyandra Rivera De Jesus, and Margaret Rossano. We would like to thank Steven Woolf for his comments on the paper.

To see this article online, please go to: http://jabfm.org/content/ 35/1/55.full.

\section{References}

1. Center for Disease Control and Prevention [Internet]. Data and statistics: current cigarette smoking among adults in the United States; 2019 [cited 2021 May]. Available from: https://www.cdc. gov/tobacco/data_statistics/fact_sheets/adult_data/ cig_smoking/index.htm.

2. Centers for Disease Control and Prevention [Internet]. National health interview survey: exercise or physical activity; 2018 [cited 2021 May]. Available from: https://www.cdc.gov/nchs/fastats/ exercise.htm.
3. Center for Disease Control and Prevention [Internet]. National health interview survey: alcohol use; 2018 [cited 2021 May]. Available from: https:// www.cdc.gov/nchs/fastats/alcohol.htm.

4. Mokdad AH, Marks JS, Stroup DF, Gerberding JL. Actual causes of death in the United States, 2000. JAMA 2004;291:1238-45.

5. National Institute of Mental Health [Internet]. Mental health information; 2021 [cited 2021 May]. Available from: https://www.nimh.nih.gov/health/ statistics/mental-illness.

6. Koh HK, Piotrowski JJ, Kumanyika S, Fielding JE. Healthy people: a 2020 vision for the social determinants approach. Health Educ Behav 2011;38: 551-7.

7. Landon BE, Grumbach K, Wallace PJ. Integrating public health and primary care systems: potential strategies from an IOM report. JAMA 2012; 308:461-2.

8. WHO Commission on Social Determinants of Health. Closing the gap in a generation: health equity through action on the social determinants of health: Commission on Social Determinants of Health final report. Geneva, Switzerland: World Health Organization, Commission on Social Determinants of Health; 2008.

9. Adler NE, Glymour MM, Fielding J. Addressing social determinants of health and health inequalities. JAMA 2016;316:1641-2.

10. Alley DE, Asomugha CN, Conway PH, Sanghavi DM. Accountable health communities-addressing social needs through Medicare and Medicaid. N Engl J Med 2016;374:8-11.

11. Krist AH, Davidson KW, Ngo-Metzger Q, Mills J. Social determinants as a preventive service: U.S. Preventive Services Task Force methods considerations for research. Am J Prev Med 2019;57:S6-S12.

12. Green LA, Cifuentes M, Glasgow RE, Stange KC. Redesigning primary care practice to incorporate health behavior change: prescription for health round-2 results. Am J Prev Med 2008;35:S347-S349.

13. Woolf SH, Glasgow RE, Krist A, et al. Putting it together: finding success in behavior change through integration of services. Ann Fam Med 2005;3 Suppl 2:S20-S27.

14. Krist AH, Woolf SH, Frazier CO, et al. An electronic linkage system for health behavior counseling effect on delivery of the 5A's. Am J Prev Med 2008;35:S350-S358.

15. Garg A, Marino M, Vikani AR, Solomon BS. Addressing families' unmet social needs within pediatric primary care: the health leads model. Clin Pediatr (Phila) 2012;51:1191-3.

16. Centers for Medicare and Medicaid Innovation [Internet]. Accountable health communities model; 2018 [cited 2021 March]. Available from: https:// innovation.cms.gov/initiatives/AHCM. 
17. Find Help (formerly Aunt Bertha) [Internet]; 2021 [cited 2021 May]. Available from: https://www. findhelp.org/.

18. Unite Us [Internet]; 2021 [cited 2021 March]. Available from: https://uniteus.com/.

19. Virginia Governor Ralph S. Northam [Internet]. Virginia to partner with Unite Us to create statewide infrastructure connecting health and social services; 2020 [cited 2021 May]. Available from: https://www.governor.virginia.gov/newsroom/allreleases/2020/december/headline-890298-en.html.

20. Knowles M, Khan S, Palakshappa D, et al. Successes, challenges, and considerations for integrating referral into food insecurity screening in pediatric settings. J Health Care Poor Underserved 2018;29:181-91.

21. Kaiser Permanente [Internet]. Community health; 2019 [cited 2021 May]. Available from: https:// about.kaiserpermanente.org/community-health/ news/survey-housing-food-isolation-major-barriersto-health.

22. Krist AH, Glenn BA, Glasgow RE, MOHR Study Group, et al. Designing a valid randomized pragmatic primary care implementation trial: the My Own Health Report (MOHR) project. Implement Sci 2013;8:73.

23. Estabrooks PA, Boyle M, Emmons KM, et al. Harmonized patient-reported data elements in the electronic health record: supporting meaningful use by primary care action on health behaviors and key psychosocial factors. J Am Med Inform Assoc 2012;19:575-82.

24. Phillips SM, Glasgow RE, Bello G, MOHR Study Group, et al. Frequency and prioritization of patient health risks from a structured health risk assessment. Ann Fam Med 2014;12:505-13.

25. Krist AH, O'Loughlin $\mathrm{K}$, Woolf $\mathrm{SH}$, et al. Enhanced care planning and clinical-community linkages versus usual care to address basic needs of patients with multiple chronic conditions: a clinician-level randomized controlled trial. Trials 2020; 21:517.

26. Institute of Medicine (U.S.) Board on Population Health and Public Health Practice. Capturing social and behavioral domains in electronic health records: phase $1 ; 2014$.

27. Institute of Medicine (U.S.) Board on Population Health and Public Health Practice. Capturing social and behavioral domains and measures in electronic health records: phase 2; 2015.

28. United States Census Bureau [Internet]. American Community Survey data; 2020 [cited 2021 March]. Available from: https://www.census.gov/programssurveys/acs/data.html.

29. Centers for Disease Control and Prevention [Internet]. PLACES: local data for better health. 500 Cities Project; 2021 [cited 2021 March].
Available from: https://www.cdc.gov/places/index. html.

30. U.S. Department of Agriculture [Internet]. USDA Economic Research Service. Food Access Research Atlas; 2021 [cited 2021 April]. Available from: https://www.ers.usda.gov/data-products/food-accessresearch-atlas/.

31. Eviction Lab [Internet]; 2021 [cited 2021 April]. Available from: https://evictionlab.org/.

32. Lindau ST, Makelarski J, Abramsohn E, et al. CommunityRx: a population health improvement innovation that connects clinics to communities. Health Aff (Millwood) 2016;35:2020-9.

33. Virginia Ambulatory Care Outcomes Research Network [Internet]. Virginia resource registry; 2021 [cited 2021 April]. Available from: https:// acorncommunityresources.cctr.vcu.edu/.

34. Ord JK, Getis A. Local spatial autocorrelation statistics: distributional issues and an application. Geographical Analysis 2010;27:286-306.

35. Yang Y, Diez-Roux AV. Walking distance by trip purpose and population subgroups. Am J Prev Med 2012;43:11-9.

36. Sugiyama T, Kubota A, Sugiyama M, Cole R, Owen N. Distances walked to and from local destinations: age-related variations and implications for determining buffer size. J Transport Health 2019;15:100621.

37. Powell LM, Slater S, Chaloupka FJ, Harper D. Availability of physical activity-related facilities and neighborhood demographic and socioeconomic characteristics: a national study. Am J Public Health 2006;96:1676-80.

38. Powell LM, Slater S, Mirtcheva D, Bao Y, Chaloupka FJ. Food store availability and neighborhood characteristics in the United States. Prev Med 2007;44:189-95.

39. Dorch EL, Bathman J, Foster D, et al. Social service availability \& proximity and the over-representation of minority children in child welfare. J Health Hum Serv Adm 2010;33:277-320.

40. Davis J, Jossefides M, Lane T, Pijawka D, Phelps M, Ritchey J. A spatial evaluation of healthy food access: Special Supplemental Nutrition Program for Women, Infants, and Children (WIC) participants. JPHMP 2019;25:S91-S96.

41. Zenk SN, Schulz AJ, Israel BA, James SA, Bao S, Wilson ML. Neighborhood racial composition, neighborhood poverty, and the spatial accessibility of supermarkets in metropolitan Detroit. Am J Public Health 2005;95:660-7.

42. Estabrooks PA, Lee RE, Gyurcsik NC. Resources for physical activity participation: does availability and accessibility differ by neighborhood socioeconomic status? Ann Behav Med 2003;25:100-4.

43. Bauer SR, Monuteaux MC, Fleegler EW. Geographic disparities in access to agencies providing income- 
related social services. J Urban Health 2015;92: 853-63.

44. Schmitt SK, Phibbs CS, Piette JD. The influence of distance on utilization of outpatient mental health aftercare following inpatient substance abuse treatment. Addict Behav 2003;28:1183-92.

45. Amiri S, Lutz RB, McDonell MG, Roll JM, Amram O. Spatial access to opioid treatment program and alcohol and cannabis outlets: analysis of missed doses of methadone during the first, second, and third 90 days of treatment. Am J Drug Alcohol Abuse 2020;46:78-87.

46. Fortney J, Rost K, Zhang M, Warren J. The impact of geographic accessibility on the intensity and quality of depression treatment. Med Care 1999;37:884-93.

47. Kaufman TK, Rundle A, Neckerman KM, Sheehan DM, Lovasi GS, Hirsch JA. Neighborhood recreation facilities and facility membership are jointly associated with objectively measured physical activity. J Urban Health 2019;96:570-82.

48. Kaczynski AT, Besenyi GM, Stanis SA, et al. Are park proximity and park features related to park use and park-based physical activity among adults? Variations by multiple socio-demographic characteristics. Int J Behav Nutr Phys Act 2014; 11:146. 


\section{Appendix}

Appendix Figure 1. Thematic maps of community need and community program location. Each black dot represents a community program that assists with the relevant domain. The lighter color represents a lower rate or prevalence of the particular measure of community need. The darker color represents a higher rate or prevalence of the particular measure of community need. The specific scale and the specific community need is noted within the box for each.

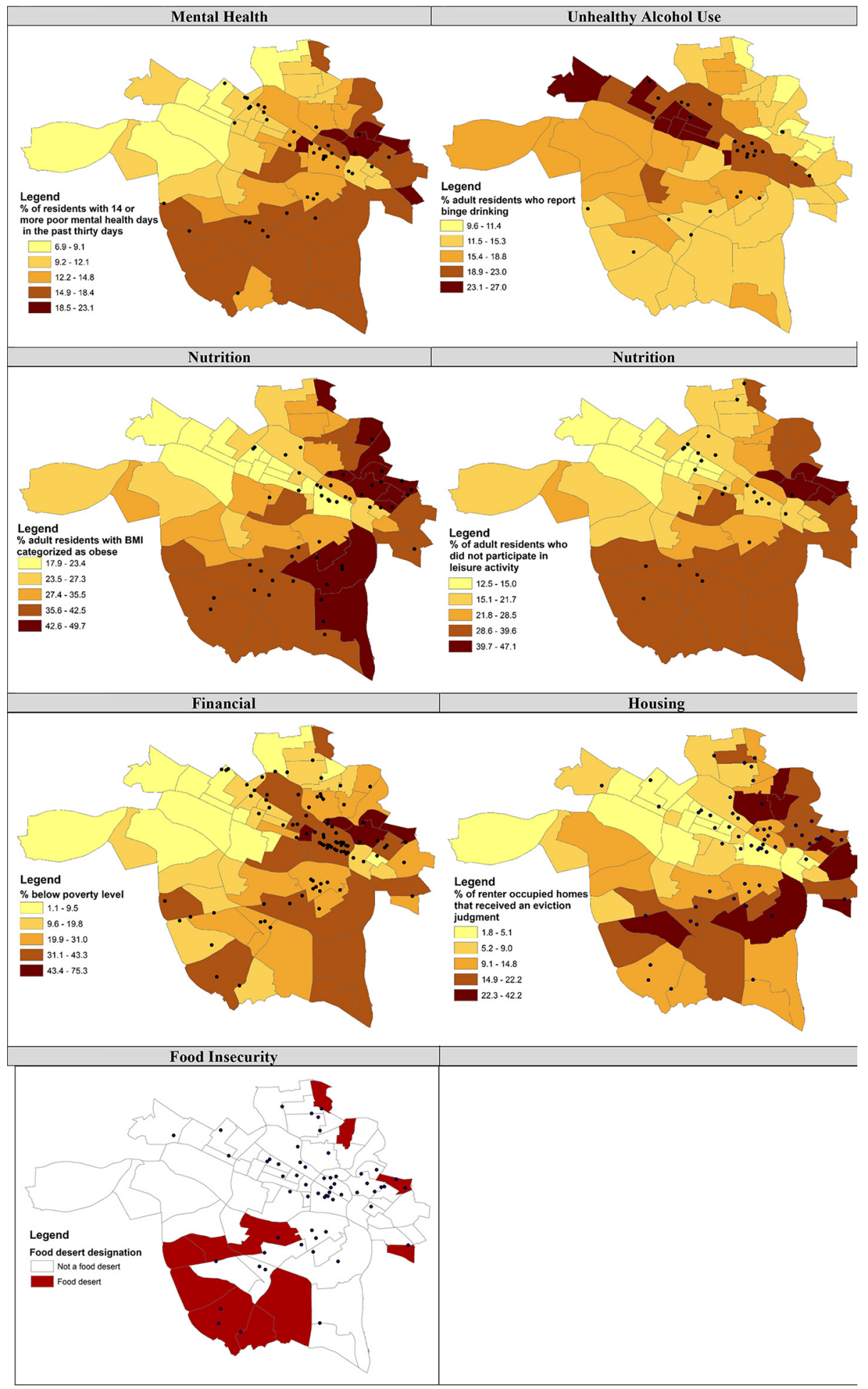


Appendix Figure 2. Sensitivity analysis of mental health.

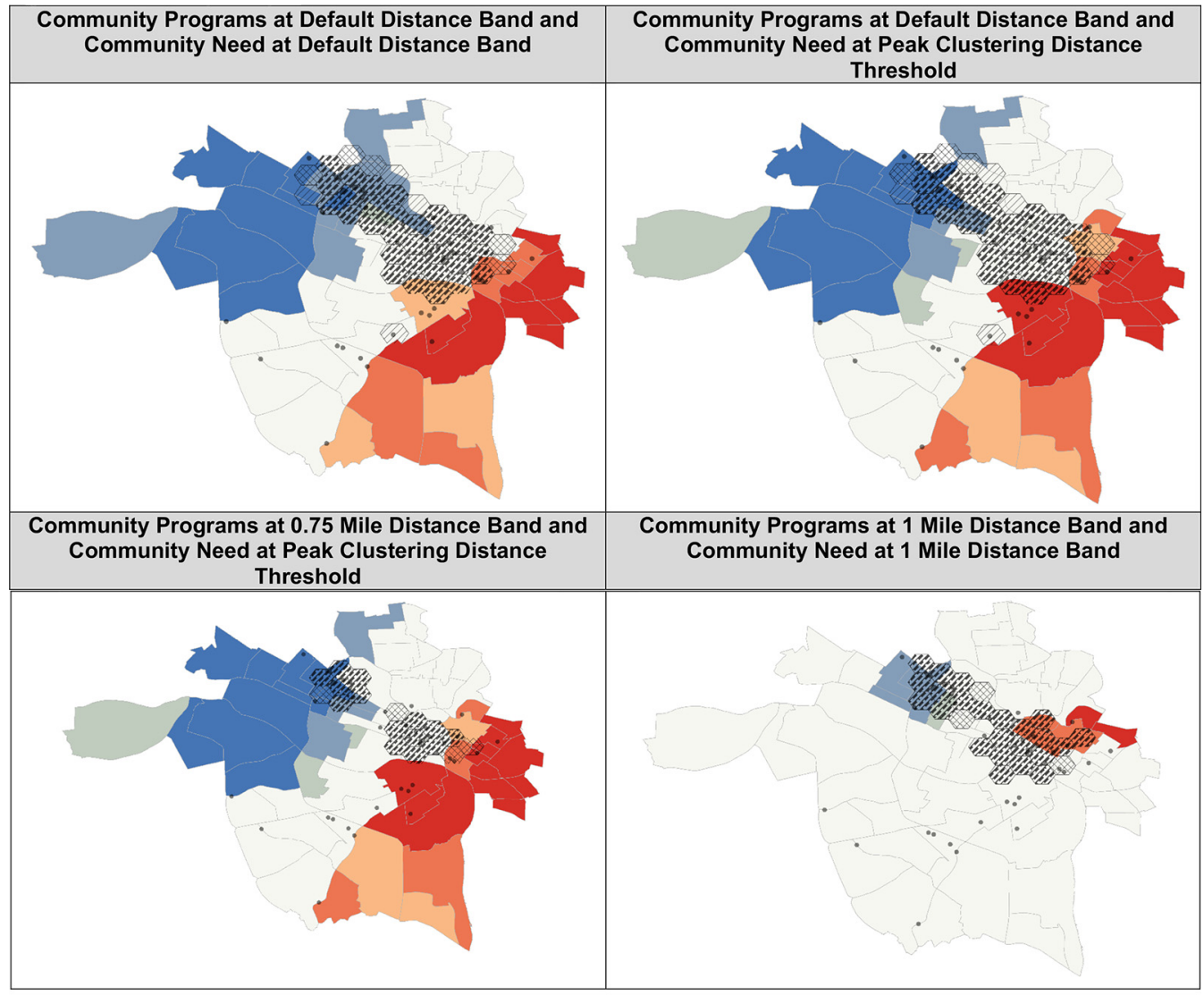

\section{Community Need}

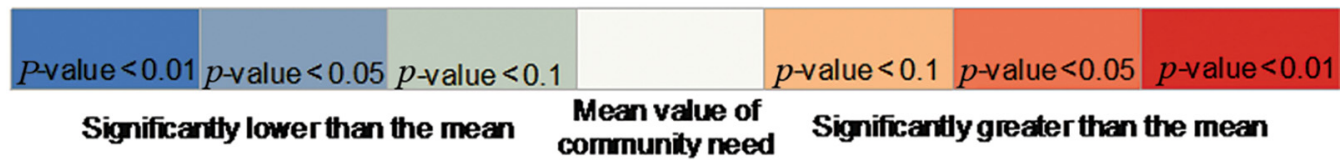

\section{Density of community programs}

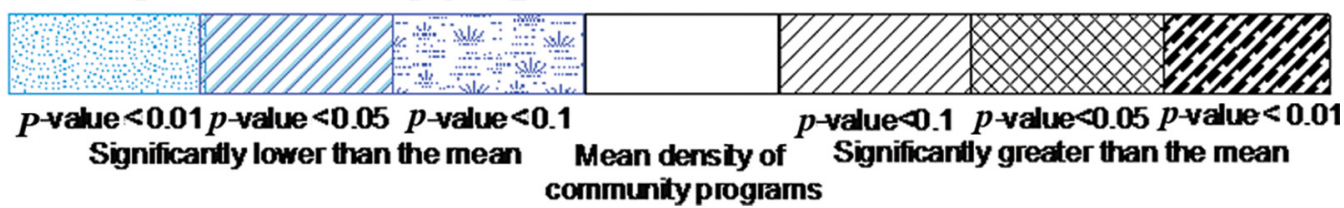

Each gray dot represents a community program that assists with the relevant domain. Hotspots of community programs (black hashes) are geospatially mapped in relation to community needs hotspots (red) versus community needs coldspots (blue). 
Appendix Figure 3. Sensitivity analysis of unhealthy alcohol use.

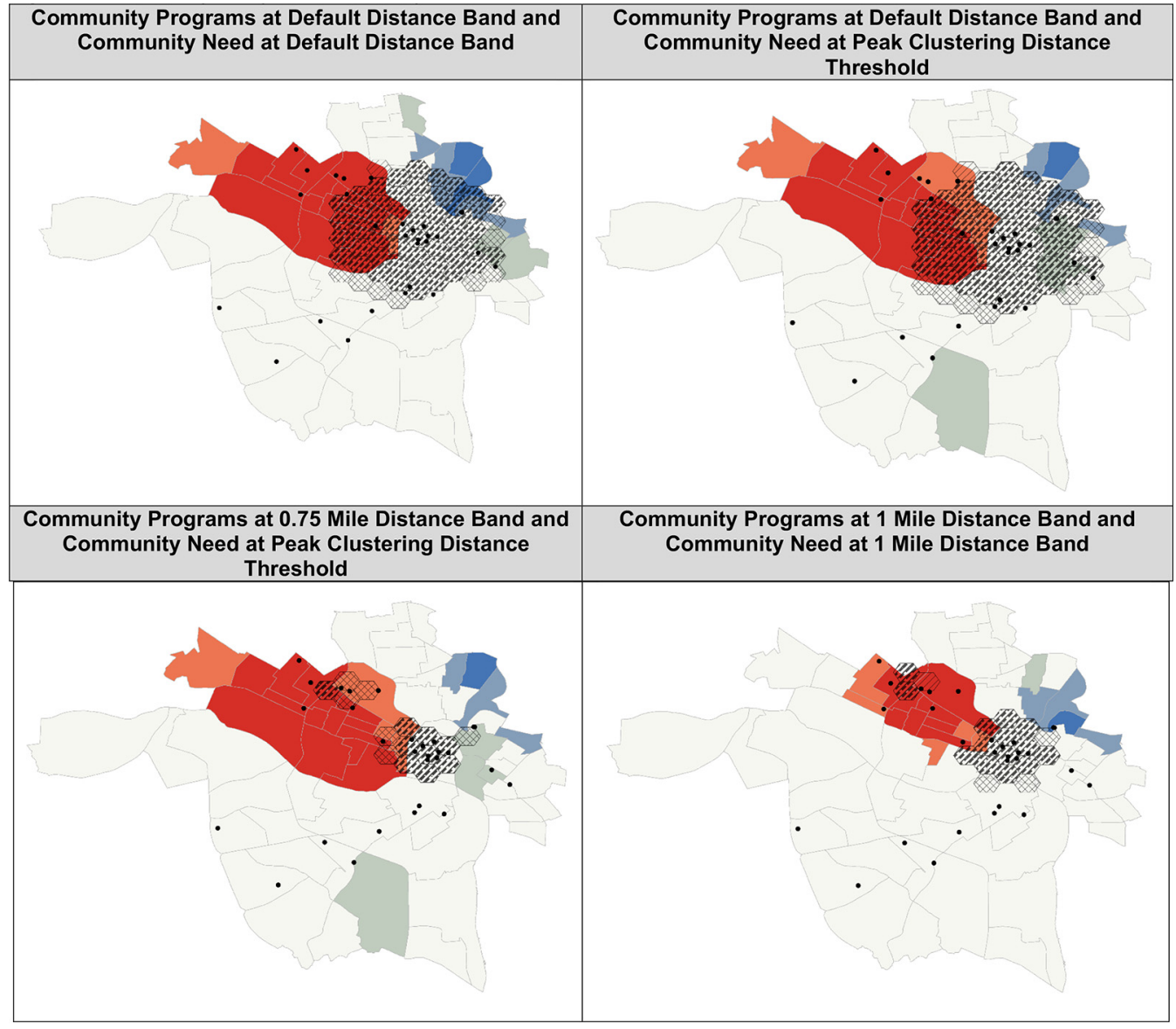

\section{Community Need}

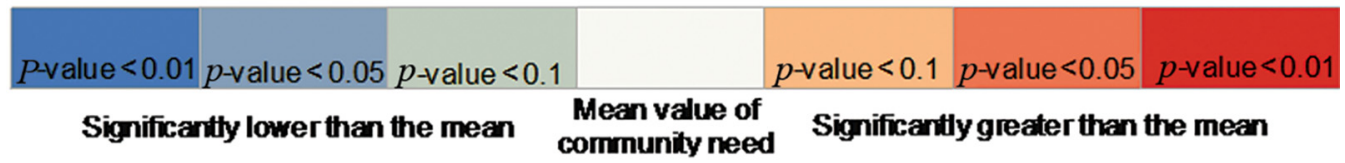

\section{Density of community programs}

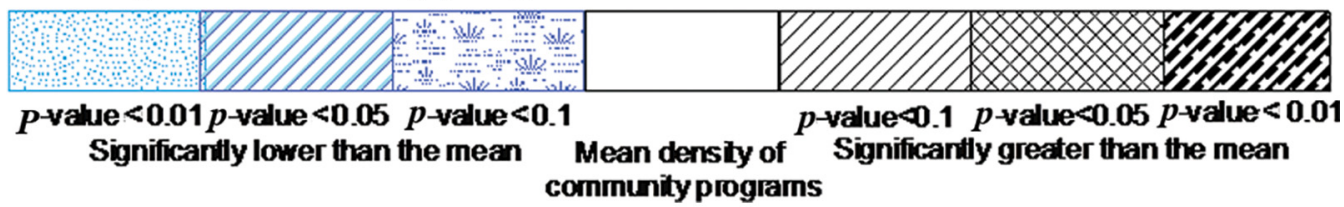

Each gray dot represents a community program that assists with the relevant domain. Hotspots of community programs (black hashes) are geospatially mapped in relation to community needs hotspots (red) versus community needs coldspots (blue). 
Appendix Figure 4. Sensitivity analysis of nutrition.

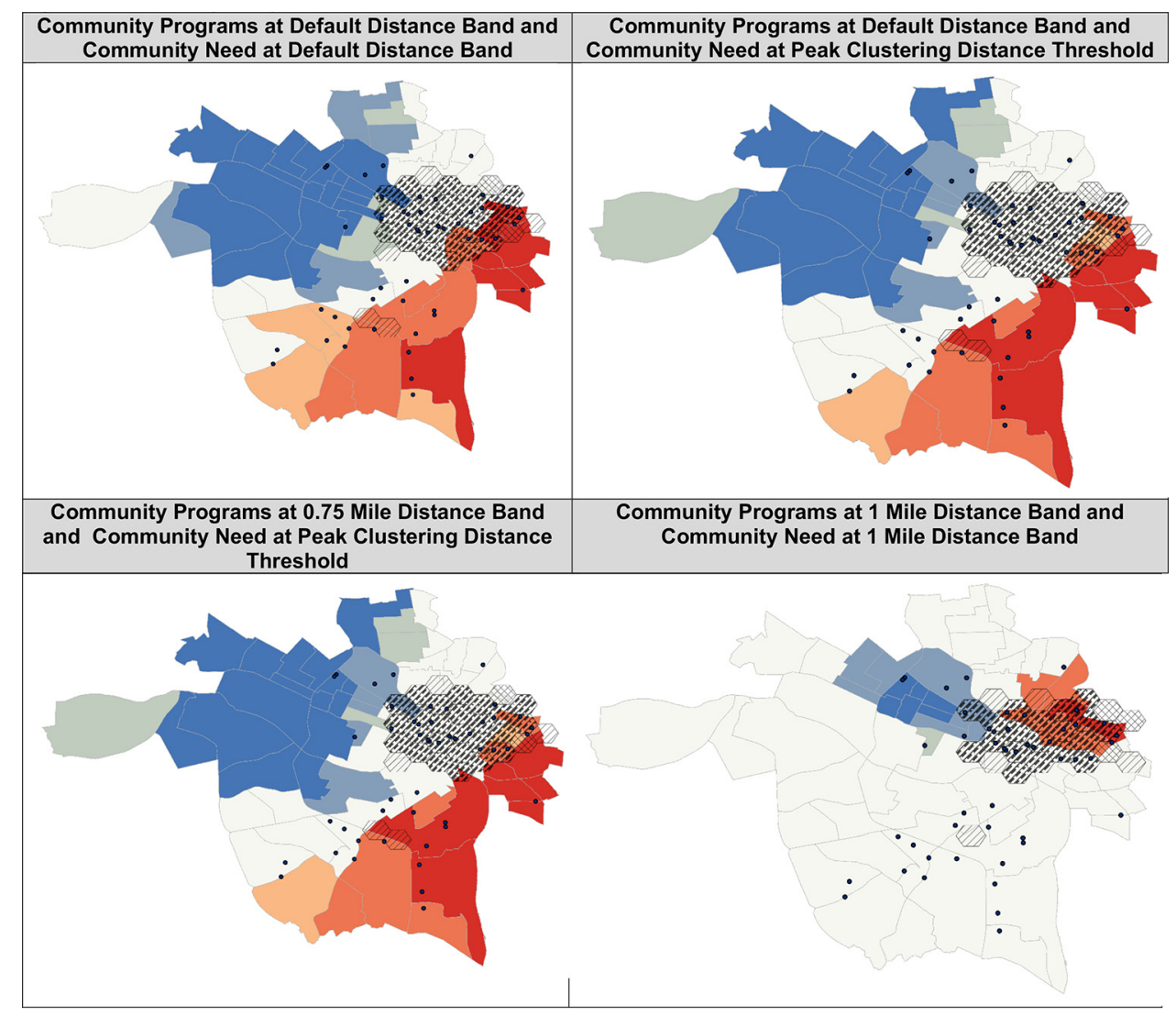

\section{Community Need}

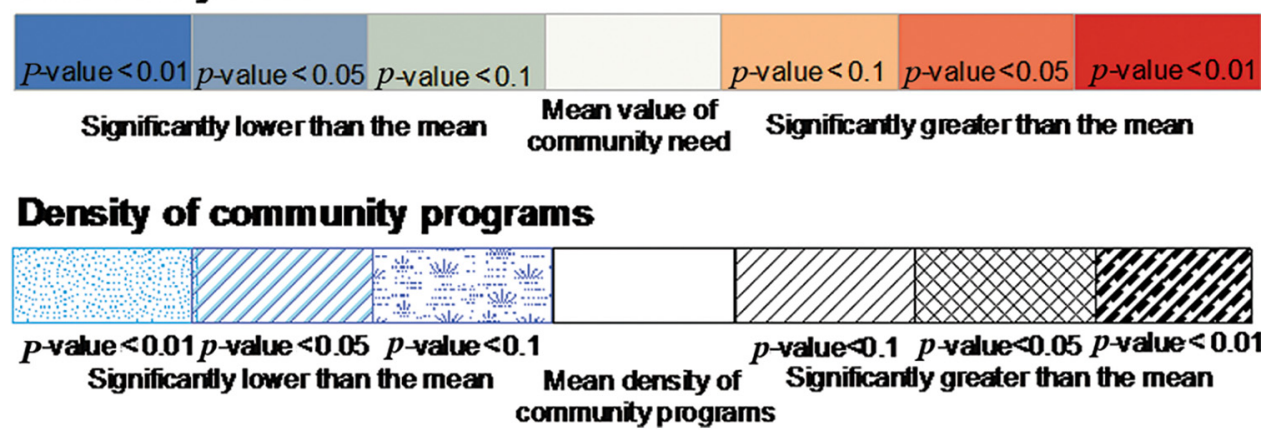

Each gray dot represents a community program that assists with the relevant domain. Hotspots of community programs (black hashes) are geospatially mapped in relation to community needs hotspots (red) versus community needs coldspots (blue). 
Appendix Figure 5. Sensitivity analysis of physical activity.

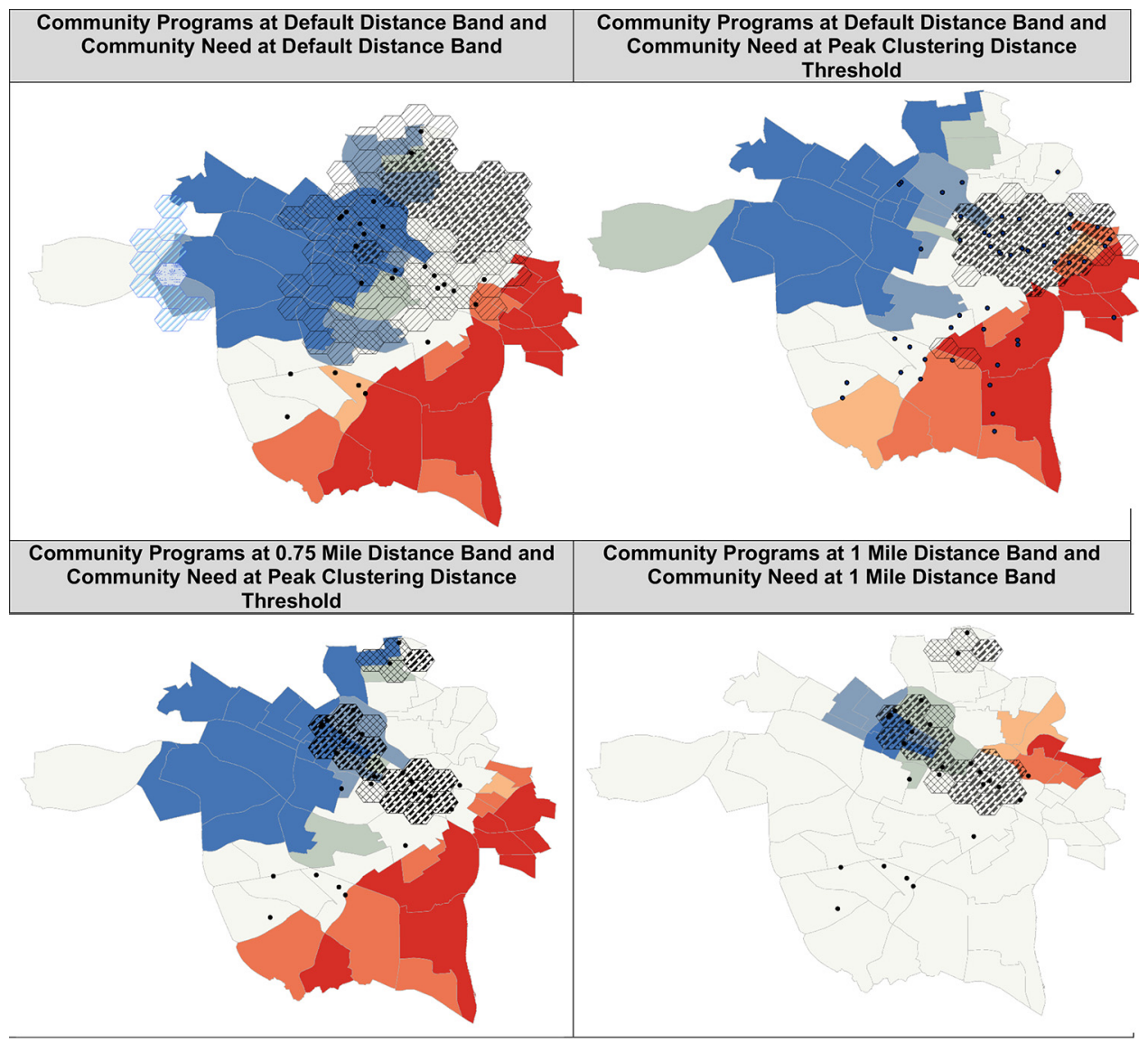

\section{Community Need}

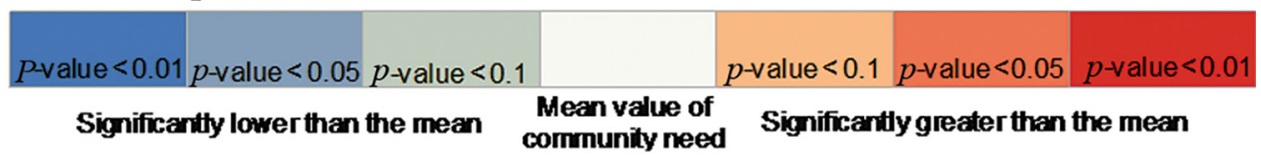

\section{Density of community programs}

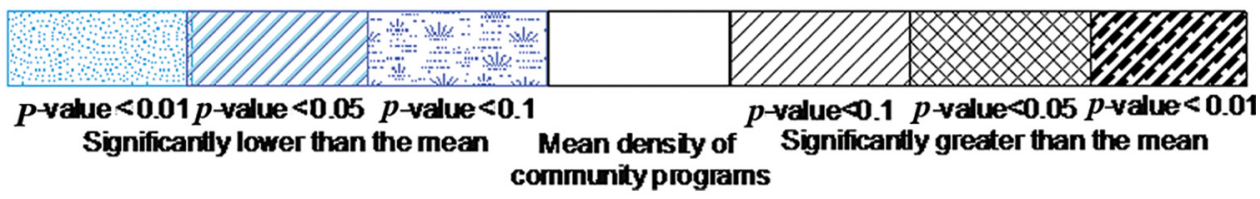

Each gray dot represents a community program that assists with the relevant domain. Hotspots of community programs (black hashes) are geospatially mapped in relation to community needs hotspots (red) versus community needs coldspots (blue). 
Appendix Figure 6. Sensitivity analysis of finance.

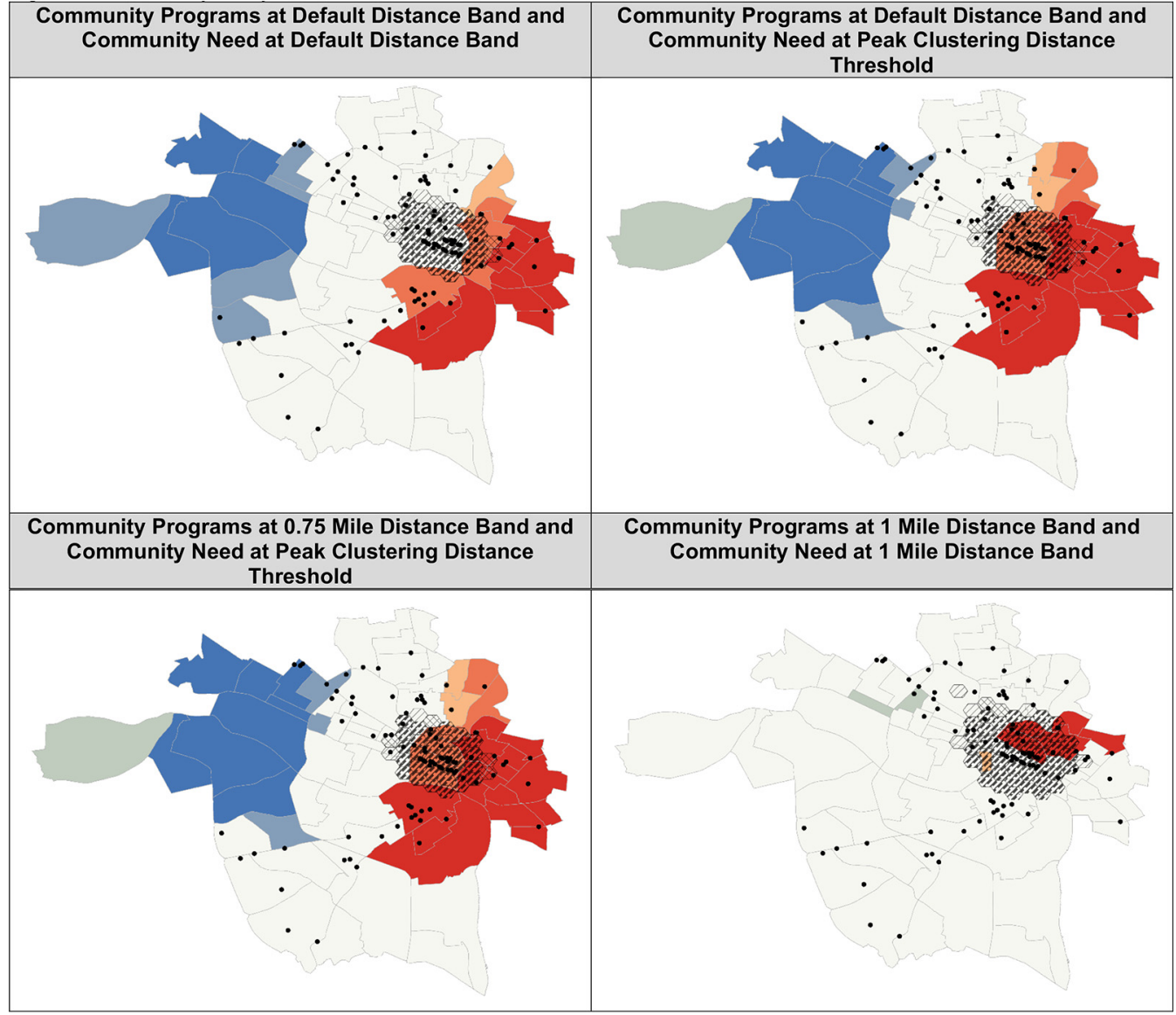

\section{Community Need}

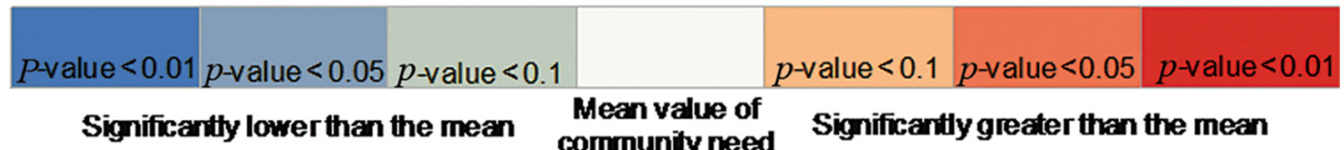

\section{Density of community programs}

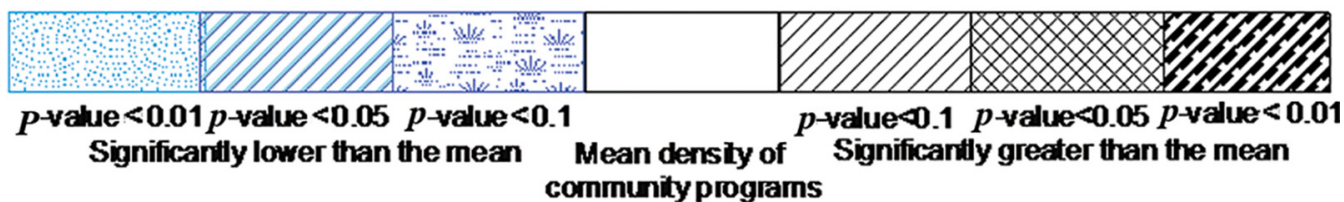

Each gray dot represents a community program that assists with the relevant domain. Hotspots of community programs (black hashes) are geospatially mapped in relation to community needs hotspots (red) versus community needs coldspots (blue). 
Appendix Figure 7. Sensitivity analysis of housing.

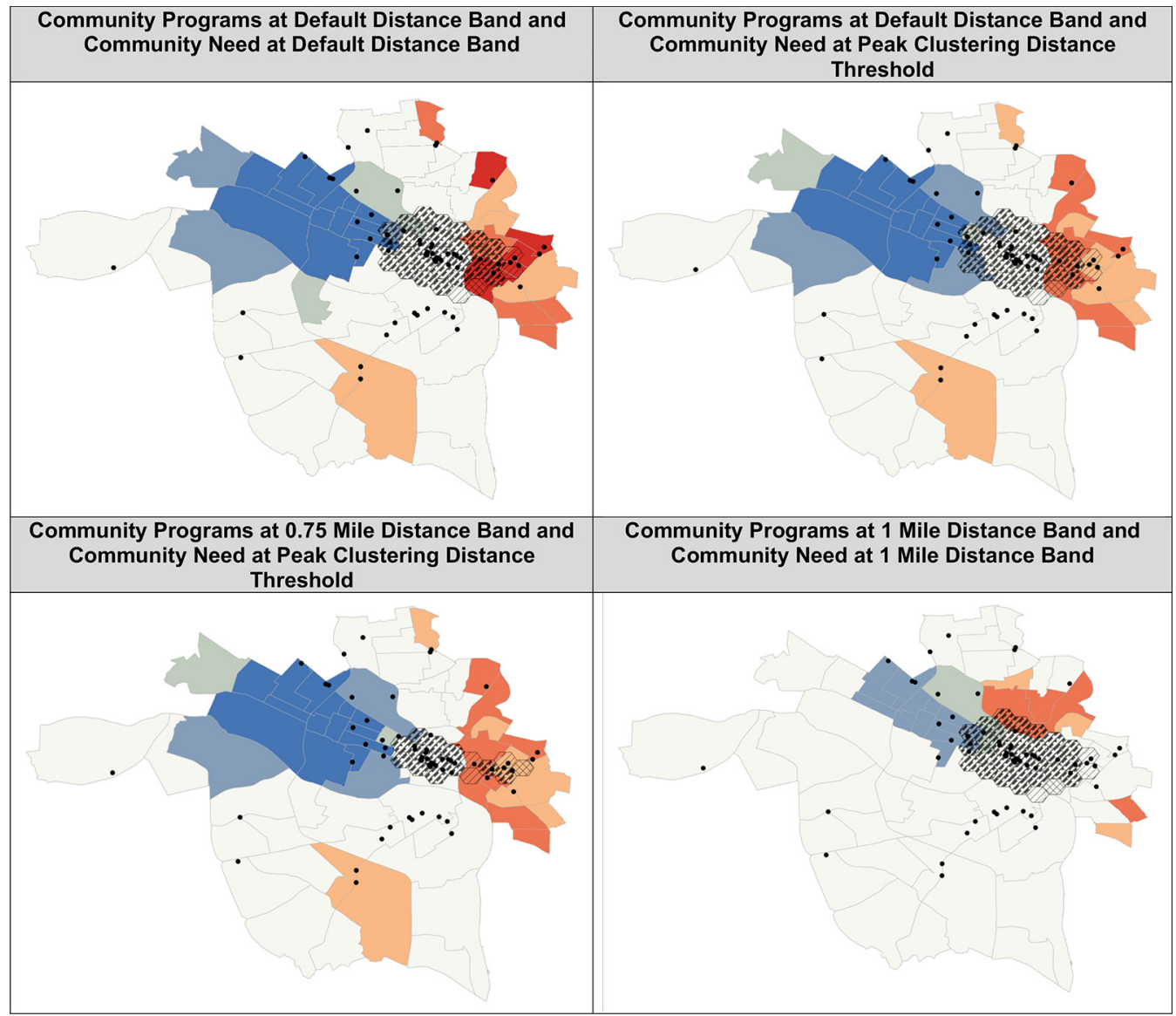

\section{Community Need}

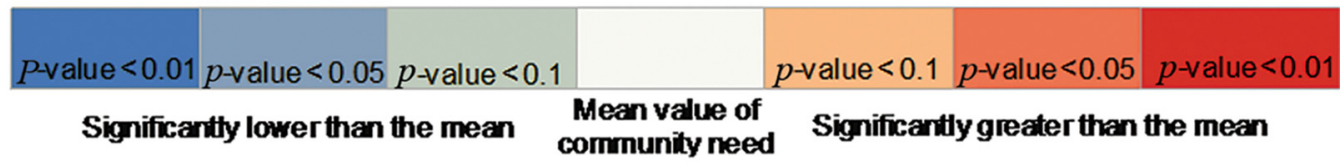

\section{Density of community programs}

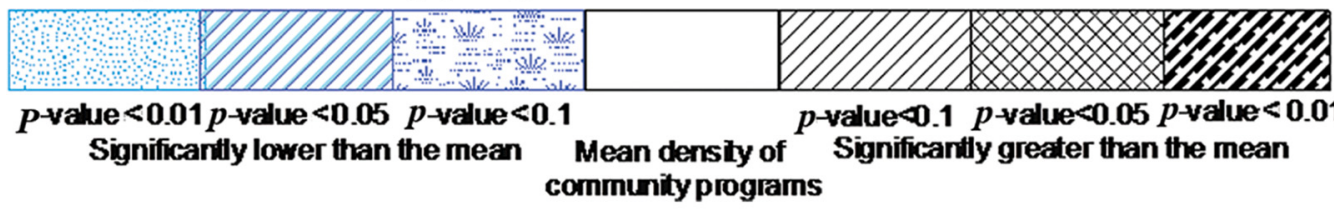

Each gray dot represents a community program that assists with the relevant domain. Hotspots of community programs (black hashes) are geospatially mapped in relation to community needs hotspots (red) versus community needs coldspots (blue). 
Appendix Figure 8. Sensitivity analysis of food insecurity.

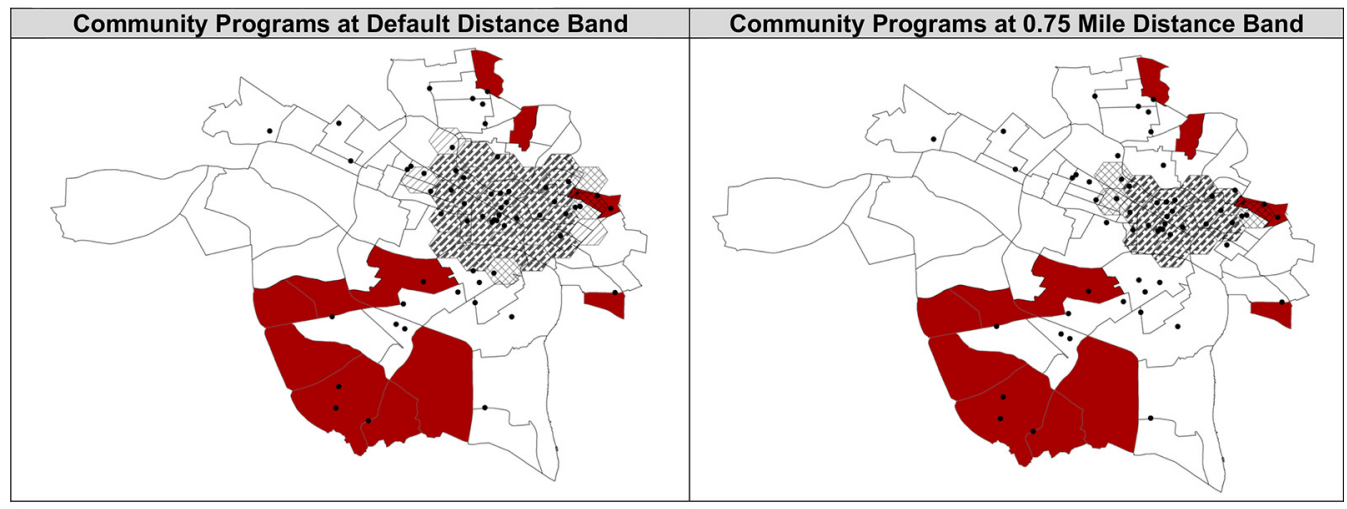

Food desert designation

$\square$ Not a food desent

\section{Food desert}

Density of community programs

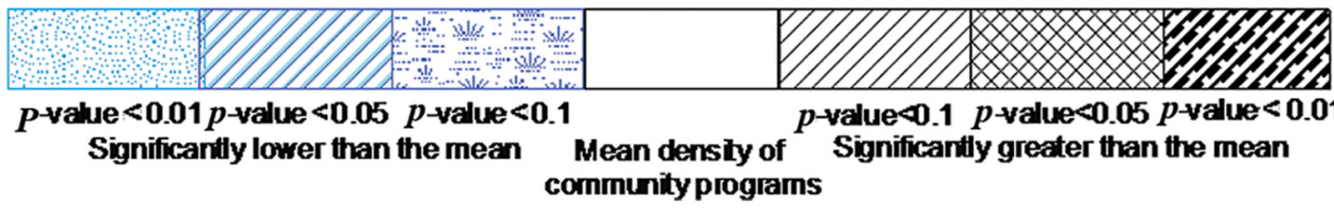

Each gray dot represents a community program that assists with the relevant domain. Hotspots of community programs (black hashes) are geospatially mapped in relation to food deserts (census tracts in red). Non-food desert census tracts are white. 